\title{
The Values of Learners' Mother Tongue Use in Target Language Classrooms
}

\author{
Yulong $\mathrm{Li}^{1}$, Lixun Wang ${ }^{1, *} \&$ Xiaojing Liu $^{2}$ \\ ${ }^{1}$ Department of Linguistics and Modern Language studies, The Education University of Hong Kong, Hong Kong, \\ China \\ ${ }^{2}$ Department of Education Policy and Leadership, The Education University of Hong Kong, Hong Kong, China \\ *Correspondence: Department of Linguistics and Modern Language studies, The Education University of Hong \\ Kong, Taipo, N.T., Hong Kong, China. E-mail:Lixun@eduhk.hk
}

Received: March 27, 2016

Accepted: June 13, $2016 \quad$ Online Published: July 9, 2016

doi:10.5430/ijelt.v3n2p46

URL: http://dx.doi.org/10.5430/ijelt.v3n2p46

\begin{abstract}
L2 (target language) exclusivity methods such as Communicative Language Teaching (CLT) have been welcomed by more and more EFL/ESL learners. However, there are scholars and practitioners who doubt the benefits of banning L1 (a learner's mother tongue) from the L2 classroom completely, and it is uncertain whether using ESL/EFL learners' mother tongue in learning the L2 is distractive. In fact, learners' use of L1 may facilitate their L2 learning in many cases. In our view, forsaking L1 when learning a target language is not holistic, and the choice of either just L2 or the combination of both L1 and L2 should be based on the needs of the students and the requirements of the relevant courses. This critique will discuss the key aspects of the use of L1 in L2 classrooms. Most importantly, a needs-based mode of L1/L2 use in an L2 classroom will be introduced and discussed.
\end{abstract}

Keywords: mother tongue; target language; L2 exclusivity; communicative language teaching; EFL/ESL

\section{Introduction}

The debate over whether L1 (a learner's mother tongue) should be allowed to be spoken in L2 (target language) classrooms, or whether the language classroom should be exclusively an L2 environment has been going on for more than half a century (Richards \& Rodgers, 1986). With the emergence of the communicative language teaching method, the tendency has been to favour L2 exclusivity as the most effective way of learning a second language (Pham, 2015; Tian \& Macaro, 2012; Turnbull \& Dailey-O'Cain, 2009). Countries and/or regions such as Hong Kong (Littlewood \& Yu, 2011) and Hungary (Nagy \& Robertson, 2009) have established exclusive L2 use as a basic rule in their second language classrooms.

However, there are those that are suspicious of the benefits of banning L1 from the L2 classroom completely. According to Macaro $(2000,68)$, 'no study has yet demonstrated a causal relation between exclusion of L1 and improved learning'. Since the 1990s, L1's contribution to L2 communication has been increasingly discussed and re-evaluated (Tian \& Macaro, 2012). Researchers have begun to examine the contribution of L1 use to the L2 learning process, focusing particularly on aspects such as cognitive processing theory and socio-cultural theory (Turnbull \& Dailey-O'Cain, 2009).

However, 'there are virtually no studies which have demonstrated that switching to the first language as opposed to maintaining second-language discourse, in specific circumstances, actually leads to better learning whether in the short term or the long term' (Macaro, 2009, 39). Researchers have found mixed views amongst teachers; for example Kharma and Hajjaj (1989) investigated teachers' opinions towards L2 exclusivity and found that beliefs about the value of L1 in the L2 classroom varied. Some L2 learners from Vietnam are found to be positive towards their teachers' code switching practice to L1 (Pham, 2015); some schools in Hong Kong even started to use learners' L1 as resources for enhancing their L2 academic literacy (Luk \& Lin, 2015). As reminded by Manar and Rhonda (2015), 
teachers understanding code switching between L1 and L2 could facilitate students learning of target language. Furthermore, according to Li and Wang (2016), many ESL/FL learners, in graduate level, not only need to learn L2 (English) literacy but also need to learn culture-contextualised, discipline-relevant, and paradigmatic-related multiple literacies; therefore, forsaking learners' L1 would not be holistic in helping them keep abreast with academic update. Therefore, this critique will discuss the key aspects of the use of L1 in the L2 classroom. Most importantly, a needs-based mode of L1/L2 use in an L2 classroom will be introduced and discussed.

\section{Key Aspects of L2 Exclusivity}

\subsection{The Underpinning Theory of L2 Exclusivity}

According to Turnbull and Dailey-O'Cain (2009), the theories underpinning the L2 exclusivity mainly draw on the hypothesis that L1=L2 based on the work of Ellis (1986), and that of Krashen $(1981 ; 1982)$ regarding the input hypothesis and Swain's (1985) output hypothesis. Furthermore, there is emphasis here on Tian and Macaro's (2012) interaction hypothesis (Long, 1981) as related to negative feedback (Dekeyser, 1993). This paper mainly focuses on the first three of these hypotheses (L1=L2 hypothesis, input hypothesis and output hypothesis). The corresponding strengths, weaknesses and constraints of L2 exclusivity related to these three hypotheses would be discussed in later sections.

\subsubsection{L1=L2 Hypothesis}

The L1=L2 hypothesis is the generally assumed supporting argument for L2 exclusivity. However, this hypothesis is also subject to debate. According to Ellis $(1985,9)$, the L1=L2 hypothesis means that 'FLA (first language acquisition) is the same as SLA (second language acquisition)'. This hypothesis is linked to a variety of perspectives, such as product, process, interactional perspective and informal-formal learning (Ellis, 1985). Interactional and informal-formal learning perspectives have greater influence on L2 exclusivity.

As Ellis $(1985,20)$ stressed, an L1=L2 hypothesis is 'most acceptable from an interactional perspective'. According to Scollon (1976), children learn L1 through face to face interaction with people and through imitating the utterances of others (Ellis, 1985). Interestingly, Hatch (1978) found that L2 competence could be improved when learners communicated with L2 native speakers. What she meant by this is that L2 native speakers' utterances work as L2 comprehensive input similar to learners' L1 input, providing frequent modelling of the use of language which would facilitate improvements in L2 learners upon exposure, just like children learning L1. Therefore, from an interactional perspective, L1 and L2 learning processes are similar, and thus the hypothesis is supported. Therefore, this perspective seems to give the impression that, just like learning L1, L2 could be achieved through learners being exposed to an L2 environment and communicating with L2 speakers. This is the essence of L2 exclusivity.

However, the interactional perspective has been criticised by Bruner (1996) who claimed that L1 learning occurs in an informal setting while L2 learning is in relatively formal contexts, such as classrooms. D'Anglejan (1978) commented that in the case of second language learning, formal learning is always less successful than informal acquisition. Indeed, this could be related to the manner in which young immigrants in L2 speaking countries acquire L2 quicker than pupils taught L2 in formal, structured classrooms. Ellis (1985) added that whether learning takes place in informal or formal contexts affects the confirmation of the L1=L2 hypothesis. This is the informal-formal learning perspective of the hypothesis which puts forward another assumption for L2 exclusivity, in that they should keep the environment as close to the real L2 environment as possible.

Beside the controversy concerning L1 $=\mathrm{L} 2$ theories, some studies have argued that the L1 $=\mathrm{L} 2$ hypothesis can only be confirmed if 'general cognitive factors' are excluded but 'purely linguistics processing' is involved (Ellis, 1985, 13). This is due to the fact that for many L1 and non-simultaneous L2 learners, age differences result in cognitive variations (Brown, 1980), suggesting that older learners apply their advanced knowledge of their L1 to their L2 learning in a way that differs from younger learners.

\subsubsection{Input Hypothesis}

Input hypothesis is the theory which further strengthens the feasibility of L2 exclusivity. The input hypothesis 'started as an account of some aspects of language processing in the 1970s, and became an all-embracing theory in the early 1980s' (Cook, 2000, 165). At present, it is not only an influential SLA theory but one that is prevalent in guiding language teaching. In order to critically discuss the input hypothesis, two other viewpoints from Krashen have to be mentioned: the acquisition-learning hypothesis and the monitor model (1981).

According to Krashen (1981), there are two possible ways of learning a second language: learning and acquisition. 
Acquisition, in this context, is understood to mean that a learner learns the L2 through subconscious, implicit, and informal processing rather than by intentionally learning rules pertaining to the grammar of the language. On the other hand, learning means to study L2 by means of formal and explicit study modes in order to understand L2 rules, patterns and grammar in an instructional setting (Brown, 2001). Different from the informal-formal learning perspective of the L1 $=\mathrm{L} 2$ hypothesis, Krashen distinguished clearly between the functions of acquisition and learning. According to Krashen (1982), the learning process and the acquisition process are divided exclusively, and learning cannot evolve to become acquisition. He also claimed that L2 fluency is a result of acquisition, which cannot be taught (Brown, 2001). This is referred to as the acquisition-learning hypothesis.

Related to this is the monitor model, which suggests that learning (not acquiring) L2 merely results in the learner having an ability to monitor the language they produced in L2 (Cook, 2000). This is described variously by Brown (2001:279) as a 'watchdogging' ability, a learned capacity for 'editing, making alterations and corrections (to what the L2 learner has produced) as they are consciously perceived'.

These two concepts provide a precondition for the input hypothesis. Krashen (1981) claimed that in order for L2 acquisition to occur, the learner should absorb and understand the inputted language at a level slightly higher than his/her L2 competence ( $\mathrm{i}+1)$. This $\mathrm{i}+1$ model is what Krashen (1981) called 'comprehensive input' which is the core of the input hypothesis. It is suggested that 'exposure to comprehensive input is both necessary and sufficient for SLL (second language learning) to take place' (Mitchell \& Myles, 2004, 165); by acquiring enough L2 comprehensive input, L2 grammar will automatically form and therefore speech will occur (Krashen, 1985). The comprehensive input and acquisition-learning hypothesis consolidates the widely held belief of learning L2 by being immersed in L2, which further underpins L2 exclusivity. However, in recent years this viewpoint has been challenged.

Firstly there is a question over how ' $\mathrm{i}+1$ ' can be identified, for example, what exactly ' $\mathrm{i}$ ' is and whether ' $\mathrm{i}+1$ ' is a usable measurement in L2 teaching contexts (Mitchell \& Myles, 2004). Secondly, those who question the acquisition-learning hypothesis and monitor model, researchers such as Ellis (1990), have found that 'learning' does indeed contribute to L2 speaking; Gregg (1984) claimed that there is not enough evidence to support a division between acquisition and learning. The third point to consider is the claim that comprehensive input does not guarantee the learners' intake (the actual absorb of L2) (Brown, 2001). To solve this problem, Seliger (1983) suggested that apart from input, learners should produce output in order to guarantee real intake.

\subsubsection{Output Hypothesis}

As another supporting theory for L2 exclusivity, many researchers have insisted that the output hypothesis complements the input hypothesis and is therefore beneficial for generating fluent L2 (Ellis \& He, 1999; de la Fuente, 2002). Swain $(1995,128)$ even extended this, by claiming that there are three strands that are a function of output: 'consciousness-raising', 'hypothesis-testing', and 'meta-linguistic function'. By 'consciousness-raising', she meant that L2 learners can be encouraged to notice their problems; by 'hypothesis-testing', she meant L2 learners can experiment with new language knowledge; by 'meta-linguistic function', she suggested that L2 learners reflect on the mistakes they have made (Mitchell \& Myles, 2004). Together these three elements comprise Swain's (1985; 1995) output hypothesis. However, Shehadeh (2002) claimed that there is a shortage of data to support the benefits of output in L2 learning. In any case, output hypothesis causes practitioners to notice the value of L2 learners' L2 reproduction, which therefore contributes to L2 exclusivity.

These three theories provide a background and an inspiration, which have led to the formation of a belief and methodology that has favoured L2 exclusivity in the language classroom. However, all these hypotheses require testing and any confirmation of them will be dependent upon further study.

\subsection{Perceived Strengths of L2 Exclusivity}

The perceived strengths of L2 exclusivity can be summarised according to four strands: providing students with a more natural L2 environment, enhancing students' L2 competence, facilitating students' L2 output, and improving learners' motivation. These are related to and build upon the basis of the three aforementioned hypotheses. These are further clarified and evaluated below.

L2 exclusivity can provide a more natural and beneficial L2 environment for acquiring L2, an environment which has more communication in L2 than the traditional instructed classroom, although it remains not truly authentic. Although many authors, e.g., Allwright and Bailey (1991), Kumaravadivelu (2003, 2006) criticise classroom use of L2 exclusivity as being artificial and not comparable with a real L2 environment, it is still real and visible to students as they spend a considerable amount of time each day in it (Crichton, 2009). Furthermore, by staying in such an 
environment, the L2 communication could be increased (Dörnyei, 2001). Therefore, even though this environment is not authentic, it does help learners produce more L2 communication and according to Crichton (2009, 26), learners' 'awareness of the language' is subsequently improved.

L2 exclusivity can be demonstrated as enhancing students' L2 competence, as was predicted by many authors (e.g., Krashen, 1982; Larsen-Freeman, 1985). For example: compared to traditionally instructed environments, when immersed in an L2 environment, students' L2 vocabulary, phrasing (Ellis \& Sinclair, 1996), pronunciation and intonation (Crichton, 2009) as a result of L2 exclusivity, improved; students also seem to achieve better comprehension levels in the L2 language (e.g., Asher 1972; Crichton, 2009); and, students' L2 repertoire appears to be enhanced (e.g., Ellis, 2001; Logan, 1998; Rost, 2002).

L2 exclusivity is also practical to facilitate students' output. According to Crichton (2009), in an L2 exclusive environment, students could stock, retrieve and use 'formulaic expressions' (sentences like 'see you tomorrow', 'thank you very much'), which become ritualised in many L2 exclusive classes (see Gatbonton \& Segalowitz, 2005; Nagy \& Robertson, 2009). Formulaic expressions are used by native speakers (Wray \& Pekins, 2000) and are believed to potentially evolve naturally into analysed L2 output (Bialystok, 1994). Thus, these formulaic expressions facilitate learners' output. Another way in which L2 exclusivity facilitates output is through expecting the students to use L2 to interact with their teachers or peers; even encountering strange meanings for which they do not have corresponding L2 expressions, a student must then resort to meaning-negotiation by applying the L2 they do know (Crichton, 2009). Therefore, through these two ways, learners' L2 output competence is enhanced.

L2 exclusivity has the potential to improve students' motivation (MacDonald, 1993). Crichton (2009) explained this in terms of intrinsic and extrinsic motivation. In the case of intrinsic motivation, when students', for example, pronunciation and intonation is improved as a result of L2 immersion, they gain more confidence to speak L2 (Crichton, 2009). With extrinsic motivation, Crichton (2009) claimed, it is the L2 exclusive environment that motivates students to speak L2 (see McMillan \& Turnbull, 2009).

\subsection{Perceived Weaknesses of L2 Exclusivity}

Critics of L2 exclusivity state that the exclusive L2 classrooms are artificial environments, which cannot replace the authentic natural L2 environment (Allwright \& Bailey, 1991). On one hand this is due to the fact that as being in an obviously artificial setting, much communication is pre-designed, whereas in a real L2 environment, social factors such as a speaker's role, different contexts, and purpose of interaction all influence the choice of language; such a holistic situation could not be sufficiently copied (Holmes, 2008). On the other hand it is also reflected in learners' motivation. According to Crichton (2009), immigrants who have moved to a new L2 environment typically experience a strong motivation to learn L2 in order to survive; however, this motivation does not apply to learners in L2 classrooms, especially those in which all learners share a common L1, who may be less burdened by necessity.

The accuracy of L2, as used by students, might diminish due to the over-reliance on meanings that proceed from L2 exclusivity (Genesee, 1994; Lapkin \& Swain, 1990). This is due to the nature of L2 exclusivity: permitting inaccurate language (Cummins, 2000), encouraging speculation over teaching meanings in differing contexts and the extent of ambiguities (Hu, 2002).

Another weakness is that L2 exclusivity is arguably less cognitively challenging for many adult learners (Cummins, 2000). This issue emerges with activities such as those used in the 'direct method' (an emphasis on repeating pronunciation and vocabulary) in order to maintain L2 exclusivity (Stern, 1992). The direct method might be useful at some point, such as when learning pronunciation, but ultimately learners would surpass this phase and aim to further understand word meanings, communicating accordingly. Due to reasons expressed by MacMillan and Turnbull (2009), such as the non-native speaker teacher's lack of L2 proficiency, the direct method is then turned to as a way to maintain L2 exclusivity. This is a problem for those mature learners who complain that tasks are insufficiently cognitively challenging (MacMillan \& Turnbull, 2009) and criticize that the learning process becomes a 'promotion of literal rather than critical comprehension' (Cummins, 2000, 10).

Generally speaking, we should note Macaro's $(2005,66)$ claim that: 'no study has yet demonstrated a causal relationship between exclusion of the first language and improved learning.'

\subsection{Realistic Constraints in Adopting L2 Exclusivity}

There are constraints, which may influence the adaption and application of L2 exclusivity; Nagy and Robertson $(2009,85)$ listed them as follows: 
- External factors: e.g. Curriculum, examinations, expectations of the school, attitudes of head-teachers, colleagues, parents and the political context;

- Internal (teacher related): Professional experience, training, proficiency in target language, self-confidence, beliefs, attitudes;

- Internal (learner related): Age, ability, proficiency, motivation, attitude;

- Internal (context related): Stage of lessons and the nature of task or activity;

- Internal (use of language): The extent to which language is predictable in the context.

The authors formulated these summarizations on the basis of their studies in Hungarian Primary schools. There are many similarities that could be shared with and generalized to other contexts, but they are a somewhat unique product of Hungarian educational culture. Apart from these aspects, the authors failed to factor in 'cultural resistance' into account of L2 exclusivity constraints. Communicative language teaching (CLT), which is a typical L2 exclusive teaching methodology, was found to be incompatible with some cultural contexts; this was observed by Chick (1996) in South Africa, Shamin (1996) in Pakistan, Pakir (1999) in Singapore, Tickoo (1996) in India and Hu (2002) in China. If we examine the case of the Chinese as an example, we see that Confucian philosophy has influenced education in China for thousands of years (Biggs, 1996; Lee, 1996; Scollon, 1999), a factor that has led to a unique 'Chinese culture of learning'; a culture, which, as explained by Hu $(2002,96)$ lays out 'a whole set of expectations, attitudes, beliefs, values, perceptions, preferences, experiences, and behaviours that are characteristics of Chinese society with regard to teaching and learning'.

Teachers in China are regarded as undisputable academic authorities $(\mathrm{Hu}, 2002)$ and they are expected to take charge of the classes which they are teaching (Tang \& Absalom, 1998). However, when applying a CLT framework, teachers are at risk of being embarrassed due to the high requirements for L2 proficiency (Hu, 2002), and are further at risk through the abandonment of the teacher dominant 'empty-vessel' approach to teaching (Maley, 1982). These challenges derive from the fact that within a CLT class, knowledge is viewed as co-constructed involving the whole class ( $\mathrm{Li}, 1984)$.

Chinese students are expected to receive, retain, repeat and review what they learn (Marton et al., 1996), largely by drawing on skills of 'meticulosity, memorisation, mental activeness, and mastery' as learning strategies (Hu, 2002, 101). Thus, they are placed in an unfamiliar and contradictory situation, when faced with the CLT method, which suggests students 'take a holistic approach to learning, downplay the importance of memorisation, stress verbal interaction, and encourage speculation and tolerance for ambiguity' (Hu, 2002, 101-102). The most valued knowledge in China is written down in literary classics and the whole process of learning is one to be taken seriously (Hu, 2002). However, in CLT, oral activities and verbal communication are the main methods of learning. Hu (2002) explains that these are incompatible with Chinese culture, and have been contributory factors to the limited success of CLT in China.

Cultural philosophy influences societal mind-sets and behaviours (Kumaravadivelu, 2008). Sometimes even though an individual might be theoretically aware of the benefits of CLT, they may be inadvertently and simultaneously influenced by their cultural philosophy and belief systems. This is why educational researchers often report that peoples' actual behaviour differs from what those same people think they did (Cohen, Manion, \& Morrison, 2011). Therefore, this evidence supports the unavoidable occurrence of cultural resistance as one of the constraints on the effectiveness of L2 exclusivity. However, this is not a comprehensive list, and it is anticipated that with more research and practice, more constraints will begin to emerge.

\section{Key Aspects of the Value of L1 Use in the L2 Classroom}

There is a growing voice in academia that argues the benefits and usefulness of L1 in the L2 learning setting (Wang, 2001; Swain, Kirkpatrick \& Cummins, 2011; Tian \& Macaro, 2012). The most influential of theories related to the use of L1 in the L2 classroom are socio-cultural theory (Brooks, Donato, \& McGlone, 1997) and cognitive processing theory (Ellis, 2005).

\subsection{Socio-Cultural Theory and the Related Value of Using L1}

Socio-cultural theory, as a related theory for the value of L1 use, has originated from the work of Vygotsky (1987) who argued that learning is not separable from learners' social interactions. In terms of L2 learning, this implies that language cannot be learned merely through learners internally processing and acquiring input, but that it requires their interaction with social contexts and other people (Bell, 2009). This differs from Krashen's (1982) hypothesis 
that suggests with enough exposure to comprehensive input, language will be acquired. There are many tenets of socio-cultural theory, the most famous of these cites language as a tool for thought and encourages scaffolding as a way of facilitating learning (Mitchell \& Myles, 2004).

Language as a tool for thought proceeds from Vygotsky's ideas about the nature of higher forms of human mental activities (Lantolf, 2000) through which humans interact with the world and manipulate themselves in relation to others (Bell, 2009). According to Lantolf (2000), the more fluent one is with a language, the better it can reflect ones' thoughts and influence his or her social behaviours. It could be assumed that L1 situations could better represent learners' thought processes than L2 learning environments, if their L2 is not as competent as their L1. This could be shown when L2 learners are required to answer some high-ranking open questions, but their L2 is not competent enough to express what is in their minds; therefore, if they have recourse to revert to their L1, they could produce competent answers.

Besides this, in the perspective of language as a tool for thought, using L1 is beneficial for creating a communicative and positive classroom environment (Turnbull \& Dailey-O'Cain, 2009). This claim is supported by many authors. Littlewood and $\mathrm{Yu}$ (2011:69) looked at this issue in terms of L1 in teacher-student relations, of which they stated that L1 use helps teachers build up 'constructive relationships' with their students, because they can communicate better; Brooks and Donato $(1994,268)$ discussed this issue from a learner's perspective, and pointed out that L1 use in L2 interaction 'is a normal psycholinguistic process that facilitates second-language production and allows the learners both to initiate and sustain verbal interaction with one another'.

Scaffolding is a process denoting help and guidance from the wiser counterpart, which could support a learner in achieving their full potential. Potentially the wiser learning partner could be a teacher or peer who can solve certain problems (Wray, 2006). According to Wood and Ross (1976) quoted in Mitchell and Myles (2004, 197), scaffolding should involve: 'recruiting interest in the task, simplifying the task, maintaining pursuit of the goal, marking critical features and discrepancies between what has been produced, and the ideal solution, controlling frustration during problem solving, demonstrating an idealized version of the act to be performed'. However, this description omits an important principle; that scaffolding should be temporary, and as the development of the learner progresses, so the scaffold should be withdrawn to reveal an autonomous learner (see Chang, Sung, \& Chen, 2002).

L1 could be seen as the precondition of scaffolding, as learners can use L1 to communicate. Anton and DiCamilla (1998) have observed that mature beginner students use L1 to scaffold each other. While Littlewood and Yu (2011: 69) commented that teachers use L1 to ensure their students understand, giving instructions and maintaining a disciplined environment as a means of 'providing necessary scaffolding'. Despite the strengths mentioned here, Hosoda $(2000,71)$ states that these are merely 'useful' consequences, expressing doubts as to whether they are truly 'beneficial' to L2 learning or acquisition.

\subsection{Cognitive Processing Theory and the Related Value of Using L1}

Cognitive processing or information processing theory stresses that the human mind is an organ that learns by processing information (Ortega, 2008). This idea emerged in part as a reaction against behaviourism, and as a consequence of the wider acceptance of human cognition (Ortega, 2008). Two important assumptions that proceed from cognitive processing theories have been welcomed by second language learning researchers: they are representation (long-term memory) and working memory (Ortega, 2008).

In terms of representation (long-term memory), Bialystok and Sharwood-Smith (1985) made a comparison to books in a library, where access can be described as the way information is collated from books in a library. The capacity of long-term memory is unlimited and it is generally composed of knowledge that could be recalled and described in a way, which even we did not realize we were able to do (Ortega, 2008). L1 use in an L2 classroom could make it easier for learners to reach and refer to long term memory. This is supported by Kern (1994), Macaro (1997), and Swain and Lapkin (2005), who found that when L2 is converted to L1, learners are able to rely on representations familiar to them. This is because learners grew up in an L1 environment, having L1 representations for things they know and have met, thus, when strange L2 is translated into learners familiar L1, they could relate to their long-term memory.

Working memory is responsible for processing information and linking it to long-term memory (Ortega, 2008). Although there is limited research into human brains and minds, many people believe that the capacity of working memory is limited (Ortega, 2008). Future research is needed to confirm this theory.

L1 can also reduce the consumption of working memory when accessing new L2 knowledge. According to Kern (1994) and Macaro (1997), L1 can reduce working memory constraints, especially in cognitively loaded tasks. This 
is because working memory is the executive device for controlled processing (Baddeley \& Hitch, 1974). Controlled processing is the information processing operation, which occurs when people encounter new and difficult information which places heavy demands on working memory (Ortega, 2008). For example, if a teacher uses L2 to explain the grammatical function of a certain L2 lexical item, the item itself and the whole explanation becomes complicated for students, demanding controlled processing with high cognitive resource use. However, if the explanation is delivered in the students' L1, it will be easier for the students to understand and accept (Kern, 1994; Macaro, 1997).

Furthermore, research by Harrington and Sawyer (1992), and Towell and Dewaele (2005) pointed out that there is an L2-L1 lag, suggesting the capacity of working memory in L2 is even smaller than that for processing L1. However, as the student progress in their L2 learning, their working memory capacity for L2 increases, thereby to some extent mitigating the L2-L1 lag (Ortega, 2008). Exposure to L2 with controlled processing may be rewarding in the longer term.

\subsection{Some Perceived Weaknesses of L1 Use in L2 Classrooms}

The most relevant fact to consider here is the excessive use of L1 once students are approved to use L1 (Turnbull \& Dailey-O'Cain, 2009). According to Atkinson $(1987,426)$, overusing L1 has some corresponding risks, as described below:

A. The teacher and/or the students begin to feel that they have not "really" understood any item of language until it has been translated.

B. The teacher and/or the students fail to observe the distinctions between equivalence of form, semantic equivalence, and pragmatic features, thereby oversimplify to the point of using crude and inaccurate translations.

C. Students speak to the teacher in the mother tongue as a matter of course, even when they are quite capable of expressing what they mean in L2.

D. Students fail to realise that during many activities in the classroom it is essential that they use only English (L2).

However, it is arguable that another point should be also added to this list. Overuse of L1 could be a contributing factor to 'dumb' L2, potentially causing learners' difficulties with communicating orally in L2. This is a genuine problem, as 'dumb English' is currently a torturous problem for EFL (English as foreign language) learners in China, Japan and South Korea (Huang \& Pan, 2011).

Generally speaking, 'there are virtually no studies which have demonstrated that switching to the first language as opposed to maintaining second-language discourse, in specific circumstances, actually leads to better learning whether in the short term or the long term' (Macaro, 2009, 39).

\section{Discussion}

The debate of L1 or L2 is unfinished and will continue until more research has been conducted to verify either school of opinion. Both L2 exclusivity and L1 use in the L2 classroom have established and recognised strengths and weaknesses. Abandonment of either might run the risk of losing the value of the other. Considering this situation, some authors have provided certain types of combinations of the two for teachers. For example, Macaro (2009) mentioned three different positions which represent mainstream practitioners' methods and attitudes towards L1 or L2 use in their lessons: virtual, maximal, and optimal positions.

The virtual position aims at imitating a pure L2 environment, which obviously favours L2 exclusivity; maximal position advocates using L2 as much as possible (Macaro, 2009). Both of these approaches view L2 as the ultimate goal and best method of L2 learning and acquisition, but have ignored the value of L1 in teaching L2. In terms of optimal position, it is meant that 'at certain moments during the teaching and learning process the use of the L1 might actually enhance learning more than by sticking to L2' (Macaro, 2009, 36). Thus he is suggesting to practitioners to use L1 or L2 at the most appropriate time. However, many authors have questioned this guidance. One voice of dissent states that function and effects of either language varies according to different contexts (Turnbull \& Dailey-O'Cain, 2009). Optimal position focuses on the respective functions of L1 and L2, but it is not a holistic opinion due to the fact that it is neither context-based nor learner-based.

Different from Macaro, Stern (1990) designed a learner-centred use of L1 and L2. In his intralingual-crosslingual 
dimension he confirmed the merits of L1 and L2, and encouraged more L1 referencing (crosslingual) when teaching beginner level learners, suggesting that as learners improve, the L2 should be referenced more frequently (intralingual). Stern's suggestion is meaningful in many aspects. However, Nation and Macalister (2010) clearly define needs into three categories: necessities, lacks and wants; Stern's guidance on teaching a beginner through use of less L2 and an advanced learner with more L2 could be merely related to learners' linguistic deficiencies or necessities, but Stern did not suggest any particular procedures in order to analyse learners' real wants or needs.

However, sufficient needs analysis can ensure the course provides proper, useful and relevant knowledge for L2 learners' potential needs (Richards, 2001); for instance, if a learner wants to learn translation in order to become a translator or interpreter, or a learner aims at practicing his or her L2 listening, there is no point in only teaching by L2 or trying to blend L1 into the teaching-learning exchange. Therefore, we argue that a more sophisticated needs-based mode, concerning learners' deficiencies, necessities and wants, should be applied when deciding which language to use in teaching $\mathrm{L} 2$.

This needs-based mode is currently not easily fulfilled nor applied, not being without constraints. Besides these constraints and weakness that confine the adoption of separate L2 exclusivity and L1 use in an L2 classroom, there are constraints that derive from conflicts between the needs-based curriculum and reality. For example, if there are too many students in a given class, it is then difficult to satisfy each student's need; also whether those learning needs are consistent with the school's curriculum objectives and goals (Richards, 2001); and whether stakeholders such as teachers, school leaders, curriculum developers and policy makers, should share their opinions with learners (Richards, 2001). Apart from these, in country like China, keeping a nationwide standardized examination with a standardized curriculum for each student, famously known as 'Gaokao' (the national college entrance examination) is helping to maintain educational fairness, being implemented and upheld by the newly-assigned minister of education in China, who also mentioned that 'if Gaokao is cancelled, the wealthier class of China may have a greater chance than the rest people of receiving good quality education' (12/4/2013, URL: http://www.edu.cn/sy_12501/20130308/t20130308_913058.shtml). Therefore, in the national context of China, it is not possible to develop a needs-based educational system in public schools.

In other words, when it is not likely to develop a needs-based mode in public schools, private institutions could be better placed to provide such a needs-based mode, as long as they have the right to develop their own curriculum. Generally speaking, in order to decide which language (L1 or L2) or in what form of combination of L1 and L2 to employ in a given learning environment, an ideal way is based on a needs analysis of learners. Both L2 exclusivity and L1 use in an L2 classroom present opportunities and limitations. However, further research is needed in order to provide a more scientific basis for both theories as well as the potential practical contribution of a needs-based mode.

\section{Conclusion}

L2 exclusivity methods such as Communicative Language Teaching have been welcomed by more and more EFL/ESL learners. However, the underpinning theories of these L2 exclusivity methods, according to the discussion of the current study, are just hypothesis. The use of L1 in the L2 classroom has been proved to be beneficial to L2 learning in many cases. As there are both strengths and weaknesses regarding L2 exclusivity and using L1 in the L2 classroom, it is not wise to look at this issue from one single perspective. When learning the target language, the choice of using L2 only or the combination of both L1 and L2 should be based on the needs of the learners, so a needs-based mode should lead to a more favorable situation in L2 learning.

\section{References}

Allwright, D., \& Bailey, K. (1991). Focus on the language classroom: An introduction to classroom research for language teachers. Cambridge, UK: Cambridge University Press.

Anton, M., \& DiCamilla, F. J. (1998). Socio-cognitive functions of L1 collaborative interaction in the L2 classroom. Canadian Modern Language Review, 54(3), 314-342. http://dx.doi.org/10.3138/cmlr.54.3.314

Asher, J. J. (1972). Children's first language as a model for second language teaching. The Internet TESL Journal, 56(3), 133-139. http://onlinelibrary.wiley.com/doi/10.1111/j.1540-4781.1972.tb05031.x/abstract

Atkinson, D. (1987). The mother tongue in the classroom: A neglected resource? ELT Journal, 41(4), 241-247. http://dx.doi.org/10.1093/elt/41.4.241

Baddeley, A. D., \& Hitch, G. (1974). Working memory. In G. H. Bower (Ed.), The psychology oflearning and 
motivation: Advances in research and theory (Vol. 8, pp. 47-89). New York: Academic Press.

Bell, N. (2009). A student's guide to the MA TESOL. London: Palgrave Macmillan.

Bialystok, E. (1994). Analysis and control in the development of second language proficiency. Studies in Second Language Acquisition, 16(2), 157-168. http://dx.doi.org/10.1017/S0272263100012857

Bialystok, E., \& Sharwood-Smith, M. (1985). Inter-language is not a state of mind: An evaluation of the construct for second language acquisition. Applied Linguistics, 6(2), 101-117. http://dx.doi.org/10.1093/applin/6.2.101

Biggs, J. B. (1996). Western misconceptions of the Confucian-heritage learning culture. In D.A. Watkins \& J.B. Biggs (Eds.), The Chinese learner: Cultural, psychological and contextual influences. Hong Kong: CERC and ACER.

Brooks, F. B., \& Donato, R. (1994). Vygotskian approaches to understanding foreign language learner discourse during communicative tasks. Hispania, 77(2), 262-274. http://dx.doi.org/10.2307/344508

Brooks, F.B., Donato, R., \& McGlone, J.V. (1997). When are they going to say 'it' Right? Understanding learner talk during pair-work activity. Foreign Language Annals, 30(4), 524-541. http://dx.doi.org/10.1111/j.1944-9720.1997.tb00860.x

Brown, H. D. (1980). Principles of language learning and teaching. New Jersey: Prentice-Hall.

Brown, H. D. (2001). Principles of language learning and teaching, Beijing: FLTRP.

Bruner, J. (1996). The Culture of Education. Cambridge/London: Harvard University Press.

Chang, K., Sung, Y., \& Chen, I. (2002). The effect of concept mapping to enhance text comprehension and summarization. The Journal of Experimental Education, 71(1), 5-23. http://dx.doi.org/10.1080/00220970209602054

Chick, K. J. (1996). Safe-talk: Collusion in apartheid education. In H. Coleman (Ed.), Society and language classroom (pp. 21-39). Cambridge, England: Cambridge University Press.

Cohen, L., Manion, L., \& Morrison, K. (2011). Research methods in education. London: Routledge.

Cook, V. (2000). Second language learning and language teaching. Edward Arnold Publisher Limited.

Crichton, H. (2009). 'Value added' modern languages teaching in the classroom: An investigation into how teachers' use of classroom target language an aid pupils' communication skills. The Language Learning Journal, 37(1), 19-34. http://dx.doi.org/10.1080/09571730902717562

Cummins, J. (2000). Language, power, and pedagogy: Bilingual children in the crossfire. Clevedon: Multilingual Matters.

D’Anglejan, A. (1978). Language learning in and out of classrooms. In Richards, J. (Ed.), Understanding second and foreign language learning. Newbury House.

De la Fuente, M. J. (2002). Negotiation and oral acquisition of L2 vocabulary. Studies in Second Language Acquisition, 24(1), 81-112. http://dx.doi.org/10.1017/S0272263102001043

Dekeyser, R. (1993). The effect of error correction on L2 grammar knowledge and oral proficiency. The Modern Language Journal, 77(4), 501-514. http://dx.doi.org/10.1111/j.1540-4781.1993.tb01999.x

Dörnyei, Z. (2001). Motivational strategies in the language classroom. Cambridge, UK: Cambridge University Press.

Ellis, N. C., \& Sinclair, S. (1996). Working memory in the acquisition of vocabulary and syntax: Putting language in good order. The Quarterly Journal of Experimental Psychology, 49(1), 234-250. http://dx.doi.org/10.1080/713755604

Ellis, N.C. (2005). At the interface: Dynamic interactions of explicit and implicit language knowledge. Studies in Second Language Acquisition, 27(2), 305-352. http://dx.doi.org/10.1017/S027226310505014X

Ellis, R. (1985). The L1=L2 hypothesis: A reconsideration. System, 13(1), 9-24. http://dx.doi.org/10.1016/0346-251X(85)90003-X

Ellis, R. (1986). Understanding second language acquisition. Oxford: Oxford University Press.

Ellis, R. (1990). Instructed second language acquisition. Oxford: Blackwell.

Ellis, R. (2001). Memory for language. In B. Robson (Ed.), Cognition and second language instruction (pp. 33-68). 
England: Cambridge University Press.

Ellis, R., \& He, X. (1999). The roles of modified input and output in the incidental acquisition of word meanings. Studies in Second Language Acquisition, 21(2), 285-301. http://dx.doi.org/10.1017/S0272263199002077

Gatbonton, E., \& Segalowitz, N. (2005). Rethinking communicative language teaching: A focus on access to fluency. The Canadian Modern Language Review, 61(3), 325-353. http://dx.doi.org/10.3138/cmlr.61.3.325

Genesee, F. (1994). Integrating language and content: Lessons from immersion. Educational Practice Reports. No. 11. National Center for Research on Cultural Diversity and Second Language Learning. Washington, DC: Centre for Applied Linguistics.

Gregg, K. (1984). Krashen's monitor and Occam's razor. Applied linguistics, 5(2), 79-100. http://dx.doi.org/10.1093/applin/5.2.79

Harrington, M., \& Sawyer, M. (1992). L2 working memory capacity and L2 reading skill. Studies in Second Language Acquisition, 14(1), 25-38. http://dx.doi.org/10.1017/S0272263100010457

Hatch, E. (1978). Discourse analysis and second language acquisition. In Hatch, E. (Ed.), Second language acquisition (pp. 401-435). Rowley, MA: Newbury House.

Holmes, J. (2008). An introduction to sociolinguistics. England: Pearson Education Limited.

Hosoda, Y. (2000). Teacher codeswitching in the EFL classroom. JALT Journal, 22(1), 69-93.

$\mathrm{Hu}, \mathrm{G}$. (2002). Potential cultural resistance to pedagogical imports: The case of communicative language teaching in China. Language, Culture and Curriculum, 15(2), 93-105. http://dx.doi.org/10.1080/07908310208666636

Huang, Z. C., \& Pan, J. P. (2011). The Factor Analysis on the "Dumb English" education problem in China. Studies in Foreign Education, 8(38), 5-8.

Kern, R. G. (1994). The role of mental translation in second language reading. Studies in Second Language Acquisition, 16(4), 441-461. http://dx.doi.org/10.1017/S0272263100013450

Kharma, N. N., \& Hajjaj, A. H. (1989). Use of the mother tongue in the ESL classroom. IRAL, 27(3), 223-235.

Krashen, S. (1981). Second language acquisition and second language learning. Oxford: Pergamon Press.

Krashen, S. (1982). Principles and practice in second language acquisition. Oxford: Pergamon.

Krashen, S. (1985). The input hypothesis: Issues and implications. Harlow: Longman.

Kumaravadivelu, B. (2003). Beyond methods: Macrostrategies for language teaching. Yale University Press.

Kumaravadivelu, B. (2006). Understanding language: From method to postmethod. London: Routledge.

Kumaravadivelu, B. (2008). Cultural globalization and language education. Yale: Yale University Press.

Lantolf, J. P. (2000). Sociocultural theory and second language learning. Oxford: Oxford University Press.

Lapkin, S., \& Swain, M. (1990). French immersion research agenda for the 90s. The Canadian Modern Language Review, 46(4), 638-674.

Larbah, M., \& Oliver, R. (2015). Code switching in ESL classrooms: a study of adult Arabic learners. English Australia Journal, 31(1), 3-18.

Larsen-Freeman, D. (1985). State of the art on input in second language acquisition. In S.M. Gass \& C.G. Madden (Eds.), Input in second language acquisition (pp. 433-444). Rowley, MA: Newbury.

Lee, W. O. (1996). The cultural context for Chinese learners: Conceptions of learning in the Confucian tradition. In D.A. Watkins \& J.B. Biggs (Eds.), The Chinese Learner: Cultural, psychological and contextual influences. Hong Kong: CERC and ACER.

Li, X. J. (1984). In defence of the communicative approach. ELT Journal, 38(1), 2-13. http://dx.doi.org/10.1093/elt/38.1.2

Li, Y., \& Wang, L. (2016). English for Academic Purposes: A New Perspective from Multiple Literacies. World Journal of English Language, 6(2), 10-18. http://dx.doi.org/10.5430/wjel.v6n2p10

Littlewood, W., \& Yu, B. (2011). First language and target language in the foreign language classroom. Language Teaching, 44(1), 64-77. http://dx.doi.org/10.1017/S0261444809990310

Logan, G. D. (1998). Towards an instance theory of automaticisation. Psychological Review 95(4), 492-527. 
http://dx.doi.org/10.1037/0033-295X.95.4.492

Long, M. H. (1981). Input, interaction and second language acquisition. Annals of the New York Acadamy of Sciences, 379, 259-278. http://dx.doi.org/10.1111/j.1749-6632.1981.tb42014.x

Luk, G. N., \& Lin, A. M. (2015). L1 as a pedagogical resource in building students' L2 academic literacy: Pedagogical innovation in a science classroom in a Hong Kong school. Multilingual education: Between language learning and translanguaging, 16-34.

Macaro, E. (1997). Target language, Collaborative learning and Autonomy. Canada: Multilingual Matters.

Macaro, E. (2000). Issues in target language teaching. In K, Field (Ed.), Issues in modern foreign language teaching (pp. 163-180). London: Routledge.

Macaro, E. (2005). Codeswitching in the L2 classroom: A communication and learning strategy. In E. Llurda, (Ed.), Non-native language teachers: Perceptions, challenges and contributions to the profession (pp. 63-84). New York: Springer.

Macaro, E. (2009). Teacher use of codeswitching in the second language classroom: Exploring 'optimal' use. In M. Turnbull \& J. Dailey-O'cain (Eds.), First language use in second and foreign language learning (pp. 35-49). Clevedon: Multilingual Matters.

MacDonald, C. (1993). Using the target language. Cheltenham: Mary Glasgow Publication.

Maley, A. (1982). Foreign language learning and the search for a new paradigm. Language Learning and Communication, 1, 123-135.

Marton, F., Wen, Q., \& Nagle, A. (1996). Views on learning in different cultures: comparing patterns in China and Uruguay. Anales de piscologia, 12(2), 123-132.

McMillan, B., \& Turnbull, M. (2009). Teachers' use of the first language in French immersion: Revisiting a core principle. In M. Turnbull \& J. Dailey-O'Cain (Eds.), First language use in second and foreign language learning (pp. 15-35). Toronto: Multilingual Matters.

Mitchell, R., \& Myles, F. (2004). Second language learning theories. London: Hodder Education.

Nagy, K., \& Robertson, D. (2009). Target language use in English classes in Hungarian primary schools. In M. Turnbull \& J. Dailey-O'Cain (Eds.), First language use in second and foreign language learning (pp. 66-86). Toronto: Multilingual Matters.

Nation, I. S. P., \& Macalister, J. (2010). Language curriculum design. London: Routledge.

Ortega, L. (2008). Understanding second language acquisition. London: Hodder Education.

Pakir, A. (1999). Connecting with English in the context of internationalization. TESOL Quarterly, 33(1), 103-114. http://dx.doi.org/10.2307/3588193

Pham, H. (2015). Learners' Perceptions of Tertiary Level Teachers' Code Switching: A Vietnamese Perspective. World Academy of Science, Engineering and Technology, International Journal of Social, Behavioral, Educational, Economic and Management Engineering, 9(6), 1936-1946.

Richards, J. C. (2001). Curriculum development in language teaching. England: Cambridge University Press.

Richards, J. C., \& Rodgers, T. S. (1986). Approaches and methods in language teaching. England: Cambridge University Press.

Rost, M. (2002). Teaching and researching listening. London: Pearson Education.

Scollon, R. (1976). Conversations with a one year old. Hawaii: University of Hawaii.

Scollon, S. (1999). Not to waste words or students: Confucian and Socratic discourse in the tertiary classroom. In E. Hinkel (Ed.), Culture in second language teaching and learning (pp. 13-27). Cambridge: Cambridge University Press.

Seliger, H., W. (1983). Learner interaction in the classroom and its effects on language acquisition. In H. W, Seliger \& M. H. Long (Eds.), Classroom oriented research in second language acquisition (pp. 246-267). Rowley, MA: Newbury House Publishers, Inc.

Shamin, F. (1996). Learner resistance to innovation in classroom methodology. In H. Coleman (Ed.), Society and the Language Classroom (pp. 105-121). Cambridge, England: Cambridge University Press. 
Shehadeh, A. (2002). Comprehensible output, from occurrence to acquisition: An agenda for acquisitional research. Language Learning, 52(3), 597-647. http://dx.doi.org/10.1111/1467-9922.00196

Stern, H. H. (1990). Issues and options in language teaching. Oxford: Oxford University Press.

Swain, M. (1985). Communicative competence: Some roles of comprehensible input and comprehensible output in its development. In S. M. Gass \& C. G. Madden (Eds.), Input in second language acquisition (pp. 235-253). Rowley, MA: Newbury House.

Swain, M. (1995). Three functions of output in second language learning. In G. Cook \& B. Seidlhofer (Eds.), Principle and practice in applied linguistics: Studies in honour of H.G. Widdowson (pp. 125-144). Oxford: Oxford University Press.

Swain, M., \& Lapkin, S. (2005). The evolving socio-political context of immersion education in Canada: Some implications for program development. International Journal of Applied Linguistics, 15(2), 169-186. http://dx.doi.org/10.1111/j.1473-4192.2005.00086.x

Swain, M., Kirkpatrick, A., \& Cummins, J. (2011). How to Have a Guilt-free Life Using Cantonese in the English Class: A Handbook for the English Language Teacher in Hong Kong. Hong Kong: Research Centre into Language Acquisition and Education in Multilingual Societies.

Tang, D., \& Absalom, D. (1998). Teaching across cultures: Considerations for western EFLteachers in China. Hong Kong Journal of Applied Linguistics, 3(2), 117-32.

Tian, L., \& Macaro, E. (2012). Comparing the effect of teacher codeswitching with English-only explanations on the vocabulary acquisition of Chinese university students: A lexical focus-on-form study. Language Teaching Research, 16(3), 367-391. http://dx.doi.org/10.1177/1362168812436909

Tickoo, M. L. (1996). Forward from Bangalore. In B. Kenny \& W. Savage (Eds.), Language and Development: Teachers in a changing world (pp. 268-280). London: Longman.

Towell, R., \& Dewaele, J. (2005). The role of psycholinguistic factors in the development of fluency amongst advanced learner of French. In J. Dewaele (Ed.), Focus on French as a foreign language: Multidisciplinary approaches (pp. 210-239). Canada: Multilingual Matters.

Turnbull, M., \& Dailey-O'Cain, J. (2009). First language use in second and foreign language learning. Toronto: Multilingual Matters.

Vygotsky, L. S. (1987). The collected works of L. S. Vygotsky: Volume 1. Thinking and Speaking. New York, NY: Plenum Press.

Wang, L. (2001). Exploring Parallel Concordancing in English and Chinese. Language Learning and Technology, 5(3), 174-184.

Wood, D., Bruner, J. S., \& Ross, G. (1976). The role of tutoring in problem-solving. Journal of Child Psychology and Psychiatry, 17(2), 89-100. http://dx.doi.org/10.1111/j.1469-7610.1976.tb00381.x

Wray, A., \& Pekins, M. R. (2000). The functions of formulaic language: An integrated model. Language and Communication, 20(1), 1-28. http://dx.doi.org/10.1016/S0271-5309(99)00015-4

Wray, D. (2006). Looking at learning. In J. Arthur, T. Grainger \& D. Wray (Eds.), Learning to teach in the primary school (pp. 46-56). London: Routledge. 